\title{
Irreversible impacts of heat on the emissions of monoterpenes, sesquiterpenes, phenolic BVOC and green leaf volatiles from several tree species
}

\author{
E. Kleist ${ }^{1}$, T. F. Mentel ${ }^{2}$, S. Andres ${ }^{2}$, A. Bohne ${ }^{1, *}$, A. Folkers ${ }^{1, * *}$, A. Kiendler-Scharr ${ }^{2}$, Y. Rudich ${ }^{3}$, M. Springer ${ }^{2}$, \\ R. Tillmann ${ }^{2}$, and J. Wildt ${ }^{1}$ \\ ${ }^{1}$ Institut für Bio- und Geowissenschaften, IBG-2, Forschungszentrum Jülich, 52425 Jülich, Germany \\ ${ }^{2}$ Institut für Energie- und Klimaforschung, IEK-8, Forschungszentrum Jülich, 52425 Jülich, Germany \\ ${ }^{3}$ Weizmann Institute of Science, Rehovot, 76100, Israel \\ *present address: MACHEREY-NAGEL, Neumann-Neander-Str. 6-8, 52355 Düren, Germany \\ ** present address: AEROPHARM, Francois-Mitterrand-Allee 1, 07407 Rudolstadt, Germany
}

Correspondence to: E. Kleist (e.kleist@fz-juelich.de)

Received: 9 July 2012 - Published in Biogeosciences Discuss.: 27 July 2012

Revised: 15 November 2012 - Accepted: 21 November 2012 - Published: 13 December 2012

\begin{abstract}
Climate change will induce extended heat waves to parts of the vegetation more frequently. High temperatures may act as stress (thermal stress) on plants changing emissions of biogenic volatile organic compounds (BVOCs). As BVOCs impact the atmospheric oxidation cycle and aerosol formation, it is important to explore possible alterations of BVOC emissions under high temperature conditions. Applying heat to European beech, Palestine oak, Scots pine, and Norway spruce in a laboratory setup either caused the well-known exponential increases of BVOC emissions or induced irreversible changes of BVOC emissions. Considering only irreversible changes of BVOC emissions as stress impacts, we found that high temperatures decreased the de novo emissions of monoterpenes, sesquiterpenes and phenolic BVOC. This behaviour was independent of the tree species and whether the de novo emissions were constitutive or induced by biotic stress.

In contrast, application of thermal stress to conifers amplified the release of monoterpenes stored in resin ducts of conifers and induced emissions of green leaf volatiles. In particular during insect attack on conifers, the plants showed de novo emissions of sesquiterpenes and phenolic BVOCs, which exceeded constitutive monoterpene emissions from pools. The heat-induced decrease of de novo emissions was larger than the increased monoterpene release caused by damage of resin ducts. For insect-infested conifers the net effect of thermal stress on BVOC emissions could be an overall decrease.
\end{abstract}

Global change-induced heat waves may put hard thermal stress on plants. If so, we project that BVOC emissions increase is more than predicted by models only in areas predominantly covered with conifers that do not emit high amounts of sesquiterpenes and phenolic BVOCs. Otherwise overall effects of high temperature stress will be lower increases of BVOC emissions than predicted by algorithms that do not consider stress impacts.

\section{Introduction}

Terrestrial vegetation is a key player in the biogeochemical cycles of carbon and water and thus a key player for Earth's climate (e.g. Carslaw et al., 2010). Therefore, possible changes in the photosynthetic capacity or transpiration by plants caused by future climatic conditions are of high importance for predicting future climate. Vegetation is an important source of reactive biogenic volatile organic compounds (BVOCs). The source strength of BVOCs exceeds that of organic volatile emissions due to human activities by an order of magnitude (e.g. Guenther et al., 1995, 2012). BVOCs play important roles in atmospheric chemistry as they are involved in photochemical ozone formation and impact the oxidative capacity of the atmosphere. Indirectly BVOCs also affect Earth's climate as they are precursors of secondary organic aerosols (Hallquist et al., 2009, and references cited therein). 
In light of these important roles, it is crucial to explore and understand possible changes in BVOC emissions under climatic changes. Vegetation models predict that, under future global climatic changes, forests in temperate and boreal regions will flourish and spread, suggesting that this expansion will increase the annual global production of BVOC (Lathiere et al., 2005). The prediction of future BVOC emissions as proposed by Lathiere et al. assumes equilibrium between vegetation and climate. However, considerable climatic changes will be apparent already within the next decades whereas vegetation propagates by only a few times $10 \mathrm{~km}$ in $100 \mathrm{yr}$ (Chen et al., 2011). Although vegetation can adapt to climate warming (Wolkovich et al., 2012), the time scale of climate change is short compared to typical adaptation times of ecosystems.

The mean temperature increase is often used to estimate future trends in BVOC emissions. However, future climatic scenarios predict frequent heat waves and modification of other environmental conditions, such as amount of rain and soil water content, probably inducing stress to vegetation (e.g. Sitch et al., 2007; Trenberth et al., 2007). It is thus expected that vegetation in many regions will be forced out of the optimal living conditions by exposing it to more intense and elongated heat waves, dryness, pollution or various diseases. It is projected that such extreme conditions will impose stress on plants. Therefore, it may not be sufficient to consider only constitutive isoprene- and monoterpene emissions in future climate scenarios. Other BVOC classes such as sesquiterpenes and oxygenated BVOCs may play an important and hitherto unconsidered role.

The most obvious abiotic stressors to vegetation that are expected with on-going climate change are more intense and elongated heat waves and droughts. To understand the impacts of both stresses on BVOC emissions requires checking their impacts separately in a first step. Here we investigated impacts of high temperature stress on BVOC emissions of well-watered plants and therefore decoupled impacts of heat from those of drought.

Projections of future BVOC emissions are often based on projected mean temperature increases and the well-known exponential temperature dependence of BVOC emissions. Mean temperature increases of a few degrees will normally not lead to temperatures high enough to cause deviations from such exponential increase. Therefore projections based on mean temperatures predict higher BVOC emissions with on-going climate change. However, during heat waves temperatures can be very high. Heat waves may put thermal stress on plants, which may alter BVOC emissions significantly.

For isoprene emissions the deviations from exponential temperature dependences are well known (Guenther et al., 1993). If effects of heat on monoterpene emissions were similar to those on isoprene, also monoterpene emissions might drop in regions where future heat waves put thermal stress on vegetation. To investigate the plant responses to heat with respect to emissions of monoterpenes, sesquiterpenes and phenolic BVOCs, we exposed plants to temperatures high enough to act as stress.

As stress impacts on BVOC emissions, we termed only those that were irreversible on a time scale of hours to days, meaning that BVOC emissions did not recover instantly to the emission pattern and strength observed before heat application. Reversible impacts of enhanced temperatures were not considered as stress impacts in this study. By doing so we checked for possible deviations from projected exponential temperature dependences of BVOC emissions.

Scots pine and European beech were used as they are widespread species of boreal and temperate forests. For comparison to beech we also studied Palestine oak as a typical Mediterranean species. To check data obtained with Scots pine, we used Norway spruce. Monoterpenes, sesquiterpenes and phenolic BVOCs were considered. It was found that the response of different BVOC classes to heat depended on the basic emission mechanism. Hence an overall clear mechanistic concept on the impacts of thermal stress on BVOC emissions could be obtained.

\section{Material and methods}

Experiments were conducted in the Jülich Plant-Atmosphere Chamber (JPAC) facility. A detailed description of the chamber setup and its performance is given in e.g. Schimang et al. (2006) and in Mentel et al. (2009). In short, the facility consisted of three borosilicate glass chambers $(164 \mathrm{~L}$, $1150 \mathrm{~L}$, and $1450 \mathrm{~L}$ ) with Teflon floors. Either one of the chambers was used as plant chamber. All chambers were operated as continuously stirred tank reactors, and each chamber was mounted in separate climate-controlled housing.

The range of photosynthetic photon flux density (PPFD) at mid-canopy height was between 0 and $800 \mu \mathrm{mol} \mathrm{m}^{-2} \mathrm{~s}^{-1}$ in the $164 \mathrm{~L}$ chamber, between 0 and $480 \mu \mathrm{mol} \mathrm{m}^{-2} \mathrm{~s}^{-1}$ in the $1150 \mathrm{~L}$ chamber, and between 0 and $360 \mu \mathrm{mol} \mathrm{m}^{-2} \mathrm{~s}^{-1}$ in the $1450 \mathrm{~L}$ chamber. Concentrations of water vapour, $\mathrm{CO}_{2}, \mathrm{O}_{3}$, and $\mathrm{NO}_{x}$ were measured as described in Schuh et al. (1997) and Heiden et al. (2003). All measurements were performed under low $\mathrm{NO}_{\mathrm{x}}$ and $\mathrm{O}_{3}$ conditions $\left(\left[\mathrm{NO}_{\mathrm{x}}\right]<300 \mathrm{ppt}\right.$, $\left.\left[\mathrm{O}_{3}\right]<1 \mathrm{ppb}\right)$.

BVOC concentrations were mostly determined using gas chromatography-mass spectrometry systems with similar configuration (Agilent GC/MSD-systems: GC HP5890 Series II + MSD HP5972A, GC HP6890 + MSD HP5973, GC HP7890 + MSD HP5975C). All GC-MS systems were equipped with on-line thermodesorption units (Gerstel, TDSG). For more details on the systems, see e.g. Heiden et al. (2003). In one long-term experiment we used a GCFID system (Airmotec HC 1010) optimized for measuring monoterpenes. For more details on this system, see Schuh et al. (1997). 
BVOC calibration was performed using a permeation source containing pure chemicals in individual vials in combination with a dynamic dilution system (e.g. Schuh et al., 1997; Heiden et al., 1999; Komenda et al., 2003; Heiden et al., 2003). Concentrations of the compounds released from the calibration source were determined from the mass loss rates of the individual compounds and the dilution fluxes. The BVOC mixing ratios were in the lower ppb range. The reproducibility of BVOC concentration measurements was in the range of $10 \%$, and the detection limits of our analytic equipment were between $1 \mathrm{ppt}$ and $5 \mathrm{ppt}$ for individual BVOCs.

Emissions from the whole upper part of the plants were studied. Plants possessed leaf areas between $0.035 \mathrm{~m}^{2}$ and $0.81 \mathrm{~m}^{2}$ and were investigated at air flows between 7 and $25 \mathrm{~L} \mathrm{~min}^{-1}$. Even the smallest individual mixing ratios of individual BVOCs were in the range of $150 \mathrm{ppt}$, i.e. well above the detection limits.

Identification of BVOCs was based on mass spectra and retention times of pure standards (Fluka/Aldrich, purity $>93 \%$ ). Some compounds were only tentatively identified by using reference mass spectra from the NBS Library. For these compounds, no individual calibration was conducted. In these cases we used the method described in Heiden et al. (2003) to quantify the concentrations.

Regarding possible changes in BVOC source strength in response to thermal stress, the most important species are those that exhibit strong BVOC emissions and that are widespread. As typical species of boreal or temperate forest, we used Scots pine (Pinus sylvestris L.), Norway spruce (Picea abies L.), and European beech (Fagus sylvatica L.). For comparison to European beech, Palestine oak (Quercus calliprinos L.) was used as a typical species of Mediterranean areas. Three to four-year-old tree seedlings were used in all measurements. The conifers were used as a proxy for plant species with storage pools for monoterpenes; the broad leaf species were used as proxy for species without storage pools. Experiments were performed with individual plants with one exception. In this one experiment monoterpene emissions from four Scots pine seedlings together were studied.

Before the experiment the Palestine oak was stored in a growth room. The other tree seedlings were stored outside near to a forest. Thus they were exposed to realistic conditions with all the impacts that plants experience in their environment. This also included insect or pathogen infestation.

In all cases the plants were left for at least 1 day in the plant chamber for adaptation before starting the experiments. After adaptation, we checked for the basic emission mechanisms by inspecting the diurnal modulation of the emissions. In particular it was tested whether or not there was a distinct dependence of the emissions on photosynthetic photon flux density (PPFD) and furthermore if there were significant emissions during darkness.

For our studies we applied a basic procedure. The plants were held at moderate chamber temperatures (between 12
Table 1. Overview of the measurements regarding the impacts of thermal stress.

\begin{tabular}{|c|c|c|c|c|}
\hline Species & $\begin{array}{l}\text { No. of } \\
\text { experiments }\end{array}$ & $\begin{array}{l}\text { Max. } \\
\text { temp. }\end{array}$ & $\begin{array}{l}\text { Duration of } \\
\text { thermal stress }\end{array}$ & Remarks \\
\hline European beech & 3 & $37-41^{\circ} \mathrm{C}$ & $1 \mathrm{~h}-3 \mathrm{~h}$ & \\
\hline European beech & 1 & $41^{\circ} \mathrm{C}$ & 5 days & $\begin{array}{l}31^{\circ} \mathrm{C} \text { for } 2 \text { days } \\
41^{\circ} \mathrm{C} \text { for } 5 \text { days } \\
24^{\circ} \mathrm{C} \text { for } 2 \text { days } \\
31^{\circ} \mathrm{C} \text { for } 2 \text { days }\end{array}$ \\
\hline Palestine oak & 1 & $44^{\circ} \mathrm{C}$ & $16 \mathrm{~h}$ & $\begin{array}{l}24^{\circ} \mathrm{C} \text { before/ } \\
\text { after heat }\end{array}$ \\
\hline Scots pine & 7 & $31-51^{\circ} \mathrm{C}$ & $1 \mathrm{~h}-2$ days & See Table 3 \\
\hline Norway spruce & 1 & $35^{\circ} \mathrm{C}$ & $9 \mathrm{~h}$ & $9 \mathrm{~h}$ \\
\hline
\end{tabular}

and $31^{\circ} \mathrm{C}$ ) for several days to control the stability of BVOC emissions and to check for their (normal) temperature and light dependence. Then the plants were exposed to elevated temperatures for time periods between $1 \mathrm{~h}$ and 5 days (see Table 1). Thereafter the plants were investigated at moderate temperatures again, i.e. at conditions comparable to those before the heat application. BVOC emissions as measured before and after the heat application at the same temperature and light intensity were compared. We considered differences of less than $10 \%$ to be indicative of negligible stress impact of the elevated temperature. When emissions before and after heat application differed significantly, the effect was ascribed to impacts of thermal stress on BVOC emissions. In all cases the plants were sufficiently watered, thus decoupling the impacts of heat from drought impacts.

The temperatures given here are chamber temperatures. Measurements with temperature sensors (Newport, type K, $\mathrm{Ni}-\mathrm{CrNi}$ ) showed that leaf temperatures were up to $4{ }^{\circ} \mathrm{C}$ higher than chamber temperatures. However leaf temperatures depended on the distance of the respective leaf from the chamber lamps and it was impossible to exactly determine dependence of needle temperature on the distance from the lamps. We suggest that mean leaf and needle temperatures were approximately 2 to $3{ }^{\circ} \mathrm{C}$ higher than chamber temperatures for the well-watered plants used here. Table 1 gives an overview of the experiments conducted with respect to heat application.

To assess the impact of heat on BVOC emissions, it is required to know the basic emission mechanisms. In particular it had to be known whether the emitted BVOCs were recently biosynthesized BVOCs (de novo emissions) or stored in plant organs prior to emission (pool emissions). These mechanisms were tested for by exposing plants to ${ }^{13} \mathrm{CO}_{2}$ $\left(99 \%{ }^{13} \mathrm{C}, \sim 350 \mathrm{ppm}\right.$, exposure durations $\sim 8 \mathrm{~h}$ ). For further interpretation we used the ratio of ${ }^{13} \mathrm{C}$-labelled over unlabelled BVOC:

$$
\begin{aligned}
R_{\text {iso }} & =\frac{\text { labelled }}{\text { unlabelled }} \\
& =\frac{\mathrm{C}(m+1)+\mathrm{C}(m+2)+\ldots+\mathrm{C}(m+n)}{\mathrm{C}(m)} .
\end{aligned}
$$

In Eq. (1), $\mathrm{C}(m)$ is the count rate obtained from the mass spectrum for the molecular ion. $\mathrm{C}(m+1)$ to $\mathrm{C}(m+n)$ are the 
count rates obtained at the masses $m+1$ to $m+n$ with $n$ being the number of $\mathrm{C}$ atoms of the respective BVOC. Equation (1) gives the ratio $R_{\text {iso }}$ of all molecules containing excess ${ }^{13} \mathrm{C}$ to the unlabelled molecules. We assume that all molecules containing excess ${ }^{13} \mathrm{C}$ were synthesized during the exposure to ${ }^{13} \mathrm{CO}_{2}$. Under this assumption, $R_{\text {iso }}$ gives the fraction of molecules biosynthesized during the time of ${ }^{13} \mathrm{CO}_{2}$ exposure. As there may be other carbon sources for BVOC biosynthesis than the carbon taken up as $\mathrm{CO}_{2}$ (Schnitzler et al., 2004), Eq. (1) gives a lower limit for the fraction of BVOC synthesized shortly prior to their emissions. The natural ${ }^{13} \mathrm{C}$ abundance of $1 \%$ per $\mathrm{C}$ atom in the BVOC was always considered in these calculations.

\section{Results}

\subsection{BVOC emissions from unstressed plants}

All investigated plants emitted only low amounts of isoprene, and therefore isoprene is not included in the further analysis and discussion. Unstressed plants emitted mainly monoterpenes (MTs) (> $85 \%)$. In some cases also emissions of phenolic BVOC originating downstream of the shikimate pathway (e.g. methyl salicylate, MeSa) or sesquiterpenes were found for European beech and Scots pine, although the plants showed no obvious symptoms of infestation or injury. We interpret these emissions as indications of slight and unintended stress. The plants were nevertheless classified as "unstressed plants" due to the small contribution of these BVOCs to the total emissions $(<10 \%)$.

European beech and Palestine oak do not possess storage organs for monoterpenes. Thus, MT emissions from these species are de novo emissions. For another Mediterranean oak, Holm oak, this was shown by Loreto et al. (1996) in ${ }^{13} \mathrm{CO}_{2}$ exposure experiments. Consistent with these observations, MT emissions from these species are nearly zero during darkness and exhibit a strong dependence on PPFD (e.g. Peñuelas and Llusiá, 1999). A PPFD dependence in parallel with low emissions during darkness was shown for the MT emissions from beech (Schuh et al., 1997) indicating negligible contributions of pool emissions from European beech (see also Fig. 1).

MT emissions from conifers originate mainly from MT diffusion from the resin ducts wherein they are stored (e.g. Janson, 1993). Accordingly the degree of ${ }^{13} \mathrm{C}$ labelling in the MT emitted from Scots pine was much lower than expected for pure de novo emissions. Even after $8 \mathrm{~h}$ of ${ }^{13} \mathrm{CO}_{2}$ exposure, $\alpha$-pinene, camphene, and $\Delta^{3}$-carene exhibited labelling ratios between 0.1 and $0.3\left(R_{\text {iso }}\right.$, Eq. 1$)$ indicating that the majority of these emissions (70-90\%) originate from storage pools, in line with other studies (Shao et al., 2001; Ghirardo et al., 2010).

For the oxygenated MT 1,8-cineole emitted from pine, a strong labelling was found, indicating that more than $90 \%$ of

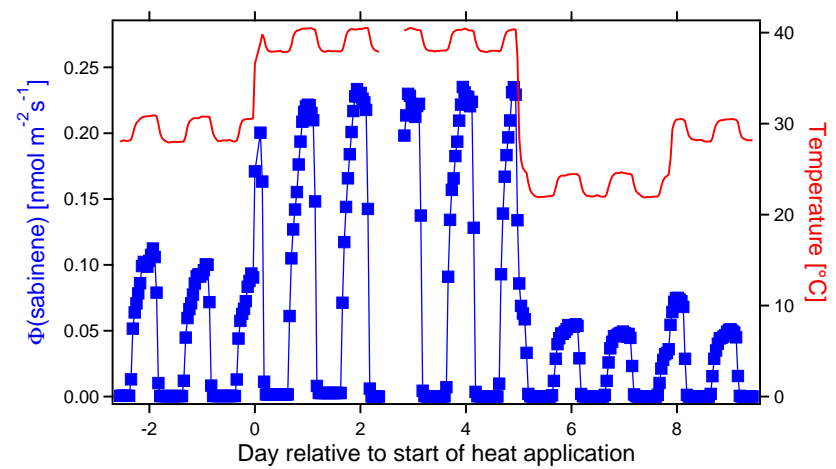

Fig. 1. Sabinene emissions (blue squares, left y-axis) from a beech. The red line indicates temperature (right y-axis). PPFD $=800 / 0 \mu \mathrm{mol} \mathrm{m}^{-2} \mathrm{~s}^{-1}$, daytime/darkness.

the emitted 1,8-cineole was synthesized from the $\mathrm{CO}_{2}$ taken up within the last 3 to $4 \mathrm{~h}$ before emission. Consistently, 1,8cineole emissions from Scots pine were negligibly low in darkness and exhibited a profound PPFD dependence (see also Tarvainen et al., 2005). This de novo emission of 1,8cineole from Scots pine enabled studying impacts of heat on de novo and on diffusive pool emissions together using a single plant (pine).

\subsection{Impact of heat on constitutive de novo monoterpene emissions}

Heat was applied to European beech and to Palestine oak, both species without storage pools. In three experiments with beech, the temperature was increased up to $41^{\circ} \mathrm{C}$ for 1 to $4 \mathrm{~h}$. Consistent with the results of Dindorf et al. (2006), we found no impacts of these short time exposures on the BVOC emissions except of the normal temperature dependence. We therefore conducted an experiment with longer-lasting heat application to a 3-yr-old beech seedling (for details see Table 1). The emission rates measured at a temperature of $31^{\circ} \mathrm{C}$ and a PPFD $=800 \mu \mathrm{mol} \mathrm{m}^{-2} \mathrm{~s}^{-1}$ before and after the heat episode were compared. The diurnal variation of MT emissions during the whole time period is shown in Fig. 1 at the example of sabinene emissions.

Figure 1 shows higher emission rates at higher temperatures. Comparing the data obtained at $31^{\circ} \mathrm{C}$ before and after applying the high temperature, we found a reduction of sabinene emissions by about $30 \%$, although rates of net photosynthesis $\left(1.9 \pm 0.5 / 2.2 \pm 0.4 \mu \mathrm{mol} \mathrm{m}^{-2} \mathrm{~s}^{-1}\right.$ before/after heat application) and transpiration (2.5 \pm $0.1 / 2.5 \pm 0.15 \mathrm{mmol} \mathrm{m}^{-2} \mathrm{~s}^{-1}$ before/after heat application) were not significantly affected. Also the sum of all MT emissions dropped by $30 \%$ from $0.19 \pm 0.01$ to $0.13 \pm$ $0.02 \mathrm{nmol} \mathrm{m}^{-2} \mathrm{~s}^{-1}$. Considering the extreme high temperature and the long application time, the decrease in MT emissions was moderate and it seemed that beech was quite resistant to pure thermal stress as long as the water supply was 
sufficient. However, the reduction in MT emissions was significant.

For comparison to European beech, we used the Mediterranean species Palestine oak. As in the case of beech, the impact of elevated temperature on MT emissions from a Palestine oak was measured by comparing the emission rates under the same conditions before and after a heat application (for details see Table 1). Compared to the emissions before the high temperature treatment, the emissions were reduced by about $50 \%$. Table 2 lists the emission rates measured for individual MTs at $24^{\circ} \mathrm{C} / 800 \mu \mathrm{mol} \mathrm{m}^{-2} \mathrm{~s}^{-1}$ before and after heat application. As shown in Table 2, absolute and relative decreases varied for the different MTs, indicating that the thermal stress had different effects on the emissions of individual MT thus not only altering emission strength but also the emission pattern. Somewhat different to the observations on beech, rates of net photosynthesis and rates of transpiration were affected by the heat. Both quantities dropped by about $50 \%$ (e.g. rate of net photosynthesis $\sim 3 / \sim 1.5 \mu \mathrm{mol} \mathrm{m}^{-2} \mathrm{~s}^{-1}$ before/after the thermal stress).

In summary, when thermal stress caused irreversible changes on de novo MT emissions from broad leaf species, MT emissions were decreased. Increased MT emissions due to impacts of thermal stress were not observed for these nonstoring species.

\subsection{Impact of heat on constitutive monoterpene emissions from pools}

Table 3 gives an overview of the experiments conducted with respect to impacts of elevated temperatures on monoterpene emissions from conifers. Three to four-year-old seedlings were used in this study. Four experiments were done with non-infested Scots pine; another four were made with insectinfested Scots pine and Norway spruce. Experiments with non-infested plants are described in this section; experiments with infested plants are described in Sect. 3.4.

Before applying elevated temperatures, the plants were kept at moderate temperatures $\left(12^{\circ} \mathrm{C}-30^{\circ} \mathrm{C}\right)$ for some days. Then the plants were exposed to temperatures between $31^{\circ} \mathrm{C}$ and $51^{\circ} \mathrm{C}$ for 1 to $48 \mathrm{~h}$. In all cases, the MT emissions increased with increasing temperature. In one case (experiment 1 in Table 3) the increases could be described by the usual exponential temperature dependence with temperature coefficients between $\beta=0.1 \mathrm{~K}^{-1}$ to $0.12 \mathrm{~K}^{-1}$. The temperature reduction after heat application also caused a reduction of the emission rates with the same temperature coefficients. Thus, after applying the enhanced temperatures, MT emissions returned to the initial values upon return to the initial conditions. This behaviour implies that the high temperatures caused a higher diffusion of MT out of the resin ducts but did not induce thermal stress with irreversible changes of BVOC emissions. In this case no emission pulses of green leaf volatiles (GLVs) were found.
Table 2. Monoterpene emissions from $Q$. calliprinos measured at a temperature of $24^{\circ} \mathrm{C}$ and a PPFD of $800 \mu \mathrm{mol} \mathrm{m} \mathrm{m}^{-2} \mathrm{~s}^{-1}$ before and after a heat application. Emission rates are the mean of at least six measurements, and the error limits represent the $1 \sigma$ standard deviations.

\begin{tabular}{llll}
\hline MT & $\begin{array}{l}\Phi_{\text {before }} \\
{\left[\mathrm{pmol} \mathrm{m}^{-2} \mathrm{~s}^{-1}\right]}\end{array}$ & $\begin{array}{l}\Phi_{\text {after }} \\
{\left[\mathrm{pmol} \mathrm{m}^{-2} \mathrm{~s}^{-1}\right]}\end{array}$ & $\begin{array}{l}\text { Ratio: after/before } \\
\text { thermal stress }\end{array}$ \\
\hline$\alpha$-thujene & $8.3 \pm 0.4$ & $4.2 \pm 0.8$ & $0.5 \pm 0.1$ \\
$\alpha$-pinene & $260.0 \pm 6.5$ & $120.0 \pm 15.2$ & $0.46 \pm 0.1$ \\
sabinene & $22.0 \pm 0.8$ & $14.0 \pm 2.4$ & $0.64 \pm 0.1$ \\
$\beta$-pinene & $93.0 \pm 2.7$ & $50.0 \pm 6.9$ & $0.54 \pm 0.1$ \\
myrcene & $11.0 \pm 0.9$ & $2.6 \pm 0.4$ & $0.24 \pm 0.04$ \\
$\alpha$-phellandrene & $5.4 \pm 0.3$ & $2.1 \pm 0.4$ & $0.39 \pm 0.1$ \\
$\alpha$-terpinene & $16.0 \pm 1.0$ & $2.3 \pm 0.5$ & $0.14 \pm 0.03$ \\
$\beta$-phellandrene & $13.0 \pm 0.6$ & $6.4 \pm 1.0$ & $0.49 \pm 0.1$ \\
$\gamma$-terpinene & $39.0 \pm 1.9$ & $1.6 \pm 0.3$ & $0.04 \pm 0.01$ \\
\hline
\end{tabular}

In contrast, in other cases (experiments 2 , and 3, in Table 3) weak but distinct pulses of GLV emissions appeared during high temperature treatments. In parallel strong MT emissions were found and, after reducing the temperature to the initial value, MT emissions remained much higher than before the thermal stress. As indicated by GLV emissions, in these cases the high temperatures caused membrane damage. We hypothesized that also membranes surrounding the resin ducts were damaged by the heat. This may have caused an increased release of MT during and after the heat application.

To test this hypothesis, a Scots pine was exposed to a short, but severe thermal stress $\left(46-51^{\circ} \mathrm{C}\right.$ for $3 \mathrm{~h}$, experiment 2 in Table 3) during an exposure to ${ }^{13} \mathrm{CO}_{2}\left(99 \%{ }^{13} \mathrm{C}, 350 \mathrm{ppm}\right.$, $8 \mathrm{~h}$ ). At the beginning of the experiment (starting from time $=0$; see Figs. 2 and 3), the pine was exposed to ${ }^{13} \mathrm{CO}_{2}$ at $28^{\circ} \mathrm{C}$, i.e. without heat application. This moderate temperature of $28^{\circ} \mathrm{C}$ was kept for $3 \mathrm{~h}$. Then the temperature was raised to about $50^{\circ} \mathrm{C}$ for $3 \mathrm{~h}$ and thereafter set back to $28^{\circ} \mathrm{C}$. The ${ }^{13} \mathrm{CO}_{2}$ exposure was stopped another $2 \mathrm{~h}$ later, as indicated by the brown bars in Figs. 2 and 3.

Before applying the heat, most of the emitted MTs were labelled to a low degree $\left(R_{\text {iso }}=0.1-0.3\right)$ indicating that 70 to $90 \%$ of these emissions were pool emissions. Nevertheless, the labelling with ${ }^{13} \mathrm{C}$ was distinct. During the third hour at elevated temperature, a strong pulse of MT emissions appeared together with a pulse of GLV emissions (not shown). Together with the onset of the MT emission pulse, the labelling of the MT decreased to non-measurable amounts. Reaching $28^{\circ} \mathrm{C}$ again after the heat pulse, the release of the stored MT was still 8-fold higher than before the thermal stress. Although exposure to ${ }^{13} \mathrm{CO}_{2}$ continued, the degree of labelling remained zero (Fig. 3).

As mentioned above, the emission of 1,8-cineole from Scots pine is a pure de novo emission. Thus, under stressfree conditions, i.e. within the first $3 \mathrm{~h}$ of the ${ }^{13} \mathrm{CO}_{2}$ exposure, we found a fast and strong labelling of 1,8-cineole $\left(R_{\text {iso }} \approx 11\right.$; see Fig. 3 ). As expected from the results obtained 
Table 3. List of experiments investigating impacts of heat on BVOC emissions from conifers and observed effects. "rev": no irreversible effect observed. "irr": irreversible effect observed with increases of pool MT emissions and decreases of SQT and MeSa emissions; "b.l." = below detection limit; "+" induced GLV emissions during the thermal stress; "-" GLV emissions not induced by the heat.

\begin{tabular}{llrrllll}
\hline Experiment & Species & Max. $T$ & Duration & MT & SQT & MeSa & GLV \\
\hline 1 & Pine & $33^{\circ} \mathrm{C}$ & $22 \mathrm{~h}$ & rev. & rev. & rev. & - \\
2 & Pine & $51^{\circ} \mathrm{C}$ & $3 \mathrm{~h}$ & irr. & b.l. & b.l. & + \\
3 & Pine & $31^{\circ} \mathrm{C}$ & $29 \mathrm{~h}$ & irr. & b.l. & b.l. & + \\
4 & Pine $^{\mathrm{a}}$ & $45^{\circ} \mathrm{C}$ & $48 \mathrm{~h}$ & irr. & a & $\mathrm{a}$ & $\mathrm{a}$ \\
$5^{\mathrm{c}}$ & Pine $^{\mathrm{b}}$ & $46^{\circ} \mathrm{C}$ & $1 \mathrm{~h}$ & rev. & rev. & rev. & - \\
$6^{\mathrm{c}}$ & Pine $^{\mathrm{b}}$ & $46^{\circ} \mathrm{C}$ & $4 \mathrm{~h}$ & irr. & irr. & irr. & + \\
$7^{\mathrm{c}}$ & Pine & $35^{\circ} \mathrm{C}$ & $22 \mathrm{~h}$ & rev. & rev. & rev. & - \\
$8^{\mathrm{c}}$ & Spruce & $35^{\circ} \mathrm{C}$ & $9 \mathrm{~h}$ & irr. & irr. & irr. & + \\
\hline
\end{tabular}

${ }^{a}$ Experiment with 4 plants together, data obtained using a GC-FID system, no reliable information on GLV, MeSa, and SQT emissions. ${ }^{b}$ Two experiments with the same individual. ${ }^{\mathrm{c}}$ Experiment with infested plants.

with European beech and Palestine oak, the behaviour of $d e$ novo emission was different from that of the $\alpha$-pinene emission representing pool emissions. Upon start of the heat application, 1,8-cineole emissions increased two fold. But, together with the onset of emissions of GLV and enhanced emissions of MT stored in the resin ducts, 1,8-cineole emissions dropped to non-measurable amounts (Fig. 3). After the thermal stress the plant was investigated for 5 more days. The pool emissions decayed exponentially, but the 1,8-cineole emissions did not recover and remained below detection limit.

This plant was exposed to extreme heat. Hence transpiration and net photosynthesis were severely affected. Transpiration collapsed nearly totally during the heat treatment but increased again directly thereafter. Few hours later it started to decrease again and, within the next two days, dropped to $20 \%$ of the value before the thermal stress (from 1.1 to $0.21 \mathrm{mmol} \mathrm{m}^{-2} \mathrm{~s}^{-1}$ ). Despite of the severity of this heat application, transpiration began to recover another day later. Until the end of the experiment ( $\sim 5$ days after the heat application), transpiration partially recovered to about $35 \%$ of the initial value $\left(0.41 \mathrm{mmol} \mathrm{m}^{-2} \mathrm{~s}^{-1}\right.$, all data for $\left.\mathrm{PPFD}=800 \mu \mathrm{mol} \mathrm{m} \mathrm{m}^{-2} \mathrm{~s}^{-1}\right)$. Net photosynthesis was more affected than transpiration. Compared to the value before the high temperature episode, net photosynthesis had decreased by more than $80 \%$ until the end of this experiment. As the plant was exposed to ${ }^{13} \mathrm{CO}_{2}$ (which is not detectable by our infrared adsorption device), no data can be given on collapsing net photosynthesis during the heat exposure.

For one experiment where Scots pine seedlings were also exposed to severe heat (experiment 4 in Table 3 ), we continued the measurements for another 6 weeks. In this experiment four Scots pine seedlings were investigated together (diurnal rhythm: $12 \mathrm{~h}$ illumination, $10 \mathrm{~h}$ darkness, and $1 \mathrm{~h}$ twilight simulated by switching on or off single lamps with a time delay of $\sim 5 \mathrm{~min}$ in the morning and in the evening,

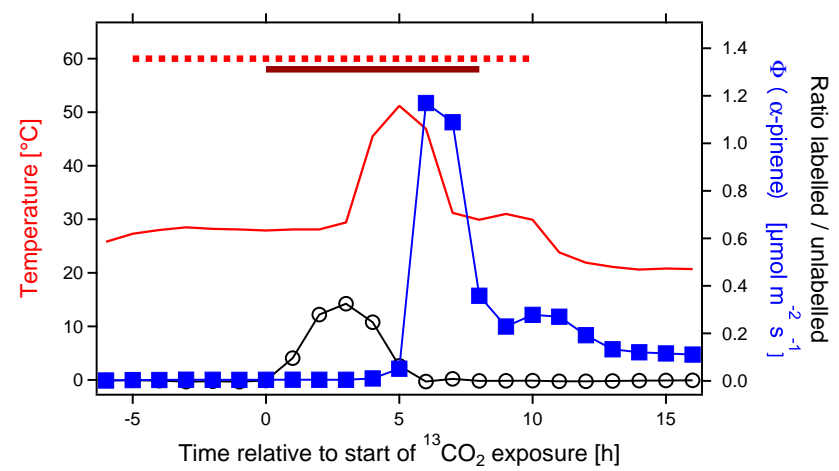

Fig. 2. $\alpha$-pinene emissions from Scots pine under thermal stress (blue squares, right-hand scale). Open circles show the labelling ratio $\left(R_{\text {iso }}\right)$ of $\alpha$-pinene molecules calculated according to Eq. (1) (black circles, right-hand scale). The red line shows the chamber temperature (left-hand scale). The dashed red bar indicates the period of illumination $\left(\mathrm{PPFD}=800 \mu \mathrm{mol} \mathrm{m} \mathrm{m}^{-2} \mathrm{~s}^{-1}\right.$ ) and the brown bar the period of ${ }^{13} \mathrm{CO}_{2}$ exposure.

respectively). PPFD during illumination varied from day to day ranging between 30 and $360 \mu \mathrm{mol} \mathrm{m}^{-2} \mathrm{~s}^{-1}$, and plant chamber temperatures were between 12 and $30^{\circ} \mathrm{C}$.

During a time period of about ten weeks (mid-April to end of June, Fig. 4), the plants were held without stress application. MT emissions were fairly stable during that time (e.g. emission rate of $\alpha$-pinene $=4 \mathrm{nmol} \mathrm{m}^{-2} \mathrm{~s}^{-1}, 1 \sigma$ standard deviation of $\pm 0.7 \mathrm{nmol} \mathrm{m}^{-2} \mathrm{~s}^{-1}$; see Fig. 4). Then the plant chamber temperature was increased to $45^{\circ} \mathrm{C}$ for $48 \mathrm{~h}$. As observed for the other pines, this heat application induced much higher MT emissions. To check for possible long-term effects, the plants were investigated further at moderate temperature conditions.

It was found that photosynthesis was strongly reduced after the high temperature episode and it took several days until the plants began to recover. However the plants recovered and 4 weeks after the thermal stress, rates of net photosynthesis and transpiration were similar to those measured before the heat treatment (difference $<20 \%$ ). In addition, MT emissions dropped back to the values similar to those before the heat application. Six weeks after the thermal stress, the plants behaved as before and showed no visible symptoms of injury.

As obvious from Fig. 4, the additional release of MT could be quite large. Estimating the total amount of released MT (compare integral MT emissions $=\Phi \cdot t$ for the time periods without and with high temperature stress in Fig. 4), the additional MT amount released due to the thermal stress could be as large as the emissions without thermal stress over a time period of several months. 


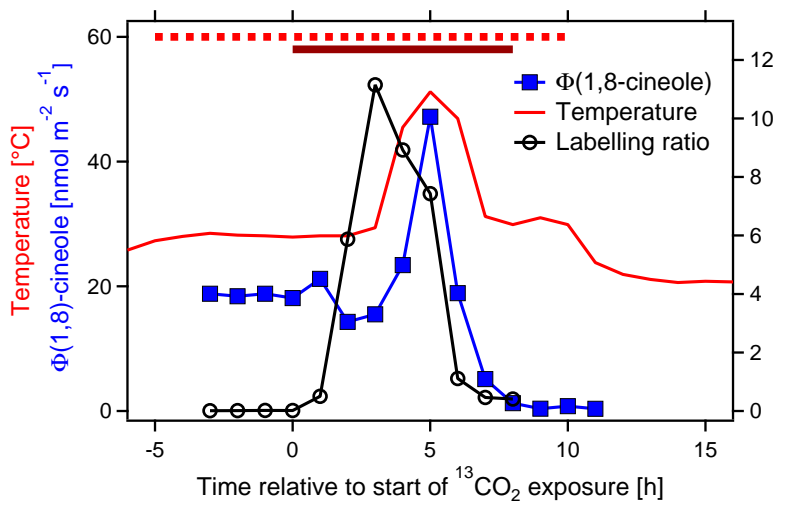

Fig. 3. Impact of high temperature stress on 1,8-cineole emissions from Scots pine (blue squares, left-hand scale). The red line shows the chamber temperature (left-hand scale). Open circles show the labelling ratio of 1,8-cineole molecules calculated according to Eq. (1), (right-hand scale). The red dashed bar shows the period of illumination (PPFD $=800 \mu \mathrm{mol} \mathrm{m}{ }^{-2} \mathrm{~s}^{-1}$ ), and the brown bar shows the period of ${ }^{13} \mathrm{CO}_{2}$ exposure.

\subsection{Impact of heat on BVOC emissions induced by biotic stress}

To investigate impacts of heat on BVOC emissions induced by biotic stress, we used selected Scots pine seedlings that were stored outside and were obviously infested by insects. The visible insects were aphids. We neither made an exact identification of the insects nor looked for other infestations than the visible ones. For our purpose it was sufficient to first check the basic mechanisms of biotic stress-induced emissions and thereafter to check the impact of heat on these emissions.

Most prominent emissions from the insect-infested Scots pine were sesquiterpenes (SQTs) and phenolic BVOCs. The emissions of $\alpha$-farnesene and $\beta$-farnesene contributed to more than $80 \%$ of the SQT emissions. Methyl salicylate (MeSa) contributed more than $80 \%$ of the phenolic BVOC emissions. Emission rates of SQT and phenolic BVOC depended on PPFD (Fig. 5).

The pronounced PPFD dependence indicated that biotic stress-induced emissions were de novo emissions. To corroborate this finding we exposed the pine to ${ }^{13} \mathrm{CO}_{2}(99 \%$ ${ }^{13} \mathrm{C}, 350 \mathrm{ppm}$, exposure time $8 \mathrm{~h}, \mathrm{PPFD}=800 \mu \mathrm{mol} \mathrm{m}{ }^{-2} \mathrm{~s}^{-1}$, temperature $=28^{\circ} \mathrm{C}$ ). As observed also for non-infested Scots pine, the MTs emitted from storage pools were only slightly labelled ( $\alpha$-pinene, $R_{\text {iso }} \sim 0.1$ ). In contrast, most SQTs (e.g. $\alpha$-farnesene, $R_{\text {iso }} \sim 28$ ) were significantly labelled, confirming that they were de novo emissions. The labelling ratio of MeSa was lower $\left(R_{\text {iso }} \sim 0.6\right)$ suggesting that parts of the MeSa were formed from stored carbon.

After the labelling experiment the plant was exposed to $46^{\circ} \mathrm{C}$ for $1 \mathrm{~h}$, but no irreversible effect was observed (experiment 5 in Table 3). The plant's emissions were measured for another week (diurnal rhythm:

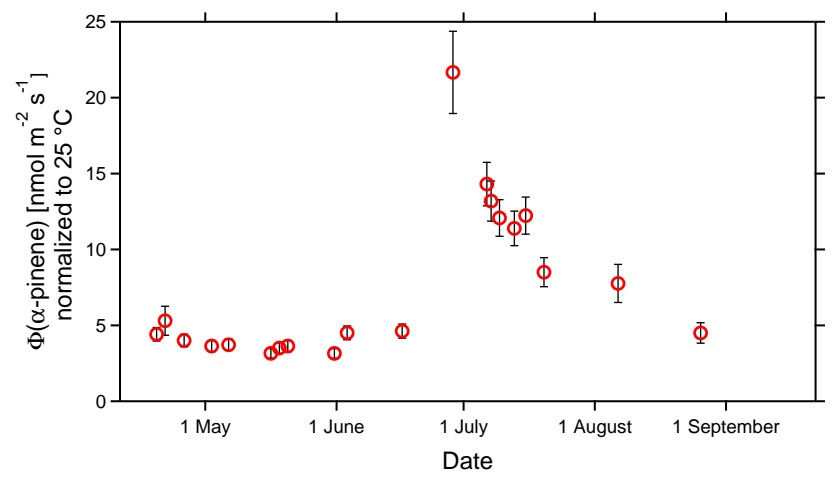

Fig. 4. Emission rates $(\Phi)$ of $\alpha$-pinene from four Scots pine seedlings. Shown are only those data obtained at $\mathrm{PPFD}=360 \mu \mathrm{mol} \mathrm{m} \mathrm{s}^{-2} \mathrm{~s}^{-1}$. Temperatures were between 12 and $30^{\circ} \mathrm{C}$, and the emission rates were normalized to $T=25^{\circ} \mathrm{C}$ using the temperature dependence given in Shao et al. (2001).

$12 \mathrm{~h}$ illumination, PPFD $=800 \mu \mathrm{mol} \mathrm{m}^{-2} \mathrm{~s}^{-1}, 1 \mathrm{~h}$ twilight in the morning and in the evening, respectively, $10 \mathrm{~h}$ darkness, PPFD $=0 \mu \mathrm{mol} \mathrm{m}{ }^{-2} \mathrm{~s}^{-1}, T=24 / 20^{\circ} \mathrm{C}$ illumination/darkness). During this period, BVOC emissions including the emissions induced by biotic stress were quite stable allowing to test the impact of thermal stress on these biotic stress-induced emissions in a second experiment with the same individual.

Exposing this plant to $46^{\circ} \mathrm{C}$ for $4 \mathrm{~h}$ caused irreversible effects (experiment 6 in Table 3). A pulse of GLV emissions appeared, and MT emissions increased by an order of magnitude. Thus the behaviour of MT emissions was the same as in case of the plants that were not infested by insects. Emissions of phenolic BVOC increased 3-fold during the heat application while SQT- and 1,8-cineole emissions dropped. After the heat application the plant was investigated again under the same conditions as prior to the heat treatment $\left(T=24^{\circ} \mathrm{C}\right.$, PPFD $=800 \mu \mathrm{mol} \mathrm{m}^{-2} \mathrm{~s}^{-1}$ ). MT emission rates were about 2-fold higher than before the heat application; emissions of SQT, 1,8-cineole and phenolic BVOC had dropped to about $1 / 3,2 / 5$ and to about $1 / 5$, respectively (Figs. 6 and 7). Five days after the high temperature treatment, 1,8-cineole had recovered but emissions of SQT and MeSa remained negligibly low. When heat induced irreversible changes of BVOC emissions, it increased pool MT emissions but decreased the de novo emissions induced by the biotic stress. As the de novo emissions were higher than the pool MT emissions before the heat application, their suppression outbalanced the increase of pool emissions (compare Fig. 6: emissions $2 \mathrm{~h}$ before heat application to emissions $52 \mathrm{~h}$ thereafter). The thermal stress decreased total BVOC emissions from this conifer.

To check if the impacts of thermal stress on top of the impacts of insect infestation were also observable for another coniferous species, we applied elevated temperature $\left(35^{\circ} \mathrm{C}\right.$ for $\left.9 \mathrm{~h}\right)$ to a Norway spruce. For this experiment we also used a plant that was stored outside before 


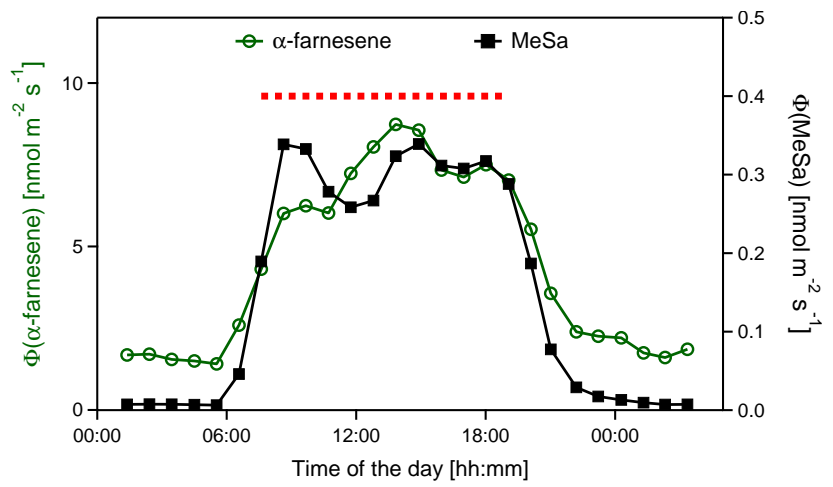

Fig. 5. Diurnal variation of the emission rates of $\alpha$-farnesene (open circles, left-hand scale) and $\mathrm{MeSa}$ (closed squares, righthand scale) measured at a chamber temperature of $20^{\circ} \mathrm{C}$ during darkness (00:00 to 05:00 and 19:00 to 00:00 LT) and at $24^{\circ} \mathrm{C}$ during illumination, respectively. The time period of full illumination $\left(\mathrm{PPFD}=800 \mu \mathrm{mol} \mathrm{m}^{-2} \mathrm{~s}^{-1}\right.$ ) is indicated by the red dashed bar.

the measurements and showed visible aphid infestation. The same general behaviour was observed for the Norway spruce as for the Scots pine. Before the heat application the spruce emitted high amounts of SQT (sum of SQT $60 \mathrm{nmol} \mathrm{m}^{-2} \mathrm{~s}^{-1}$ ) and MT (sum of MT $\sim 43 \mathrm{nmol} \mathrm{m}^{-2} \mathrm{~s}^{-1}$ ) and remarkable amounts of phenolic BVOC (sum of phenolic BVOC $\sim 4 \mathrm{nmol} \mathrm{m}^{-2} \mathrm{~s}^{-1}$ ). In particular, emissions of the SQT $\beta$-farnesene $\left(\sim 35 \mathrm{nmol} \mathrm{m}^{-2} \mathrm{~s}^{-1}\right)$ and $\alpha$-farnesene $\left(\sim 17 \mathrm{nmol} \mathrm{m}^{-2} \mathrm{~s}^{-1}\right)$ were quite high before the heat application. After the heat treatment, the biotic stress-induced emissions of SQT and phenolic BVOC decreased to low amounts but pool MT emissions were higher than before. With progressing time, pool emissions decreased again but de novo emissions did not recover within three days. Three days after exposing the plant to heat, the total amount of emitted BVOC was lower than before the heat application.

Including the data obtained for plants without obvious insect attack (Sect. 3.3), eight experiments were conducted on the impacts of elevated temperatures on BVOC emissions from boreal conifers (see Table 3). In three cases no impacts on the emissions were observed except for the normal temperature dependence. In five cases there were irreversible impacts on BVOC emissions. No relationship was found between occurrence of thermal stress impacts on the emissions and the maximum applied temperature.

\section{Discussion}

Significant parts of Earth's vegetation, especially in middle and high latitudes, will experience more frequent heat waves and drought periods as a consequence of climate change. Heat and drought periods are often coupled. Thus the impact of heat may be enhanced by parallel drought, because reduction of transpiration causes less cooling of leaves. During

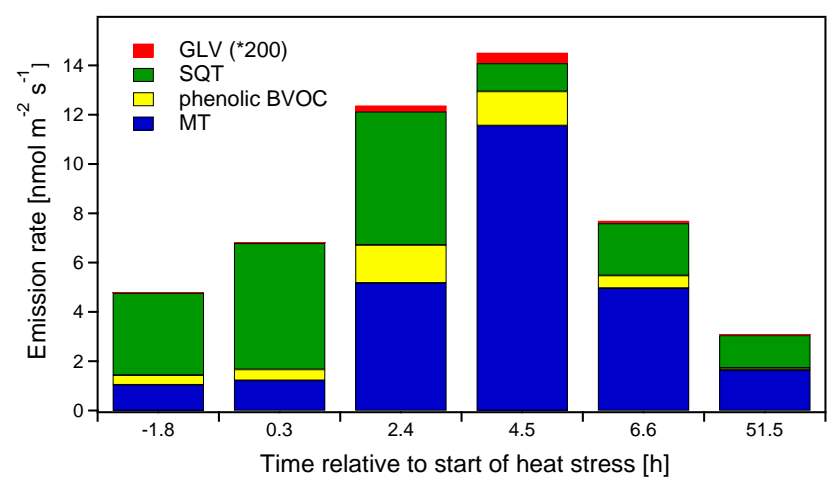

Fig. 6. Emission rates for different BVOC classes before, during and after a thermal stress application to an insect-infested pine. Blue bars = sum of MT emissions; yellow bars = sum of phenolic BVOC; green bars = sum of SQT emissions; red bars = sum of GLV emissions multiplied by 200 for visibility. Numbers at the $\mathrm{x}$-axis indicate the time of measurement relative to starting thermal stress $\left(46^{\circ} \mathrm{C}, 4 \mathrm{~h}\right)$.

drought periods, leaf temperatures may exceed air temperatures (e.g. Hamerlynck and Knapp, 1994; Singsaas et al., 1999). Hence, the temperatures used here to apply thermal stress were not unrealistically high and may occasionally be reached in future climate. As a consequence of these stresses, BVOC emissions will change. Considering the basic emission mechanisms, this seemingly complex system can be unravelled at least qualitatively on a mechanistic basis.

We first separate the emissions of green leaf volatiles (GLV) from other BVOC emissions, because GLV emissions behave differently from the other de novo emissions. Thereafter, we investigate terpenoid emissions and consider the two basic emission mechanisms: de novo emissions and pool emissions. As a last step we focus on the impacts of high temperature stress on the BVOC emissions induced by biotic stress.

\subsection{GLV emissions in response to heat}

Green leaf volatiles are synthesized via a sequence of enzymes within the octadecanoid pathway. Due to their instantaneous release shortly after their biosynthesis (e.g. Fall et al., 1999), we consider GLV emissions as de novo emissions although we found neither ${ }^{13} \mathrm{C}$ labelling nor any distinct diurnal variation. The lack of labelling in GLV emissions is most probably due to insignificant labelling of the substrate. GLVs are produced from membrane lipids that were synthesized long before the exposure to ${ }^{13} \mathrm{CO}_{2}$. Thus the ${ }^{13} \mathrm{C}$ abundance in these membrane lipids is similar to the natural ${ }^{13} \mathrm{C}$ abundance. Significant degree of labelling therefore cannot be expected for the GLV. Furthermore, GLV emissions appear as pulses exhibiting high temporal dynamics (see Heiden et al., 2003; Beauchamp et al., 2005). Therefore typical 


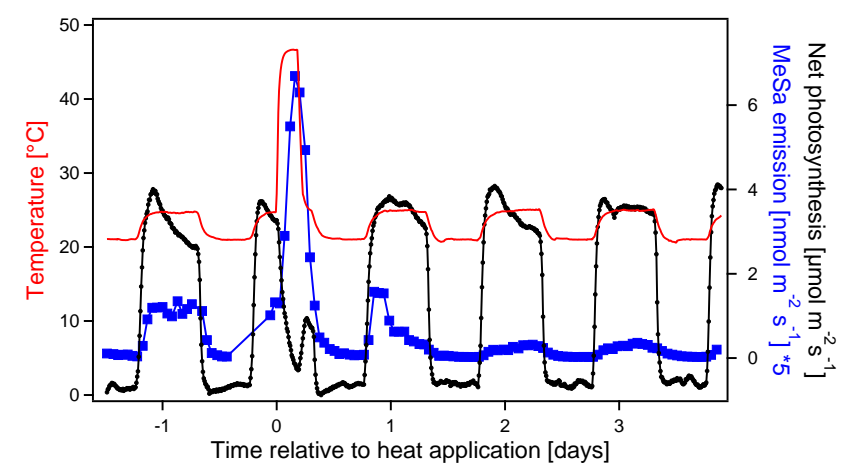

Fig. 7. Temporal shape of temperatures applied to Scots pine in experiment No. 6 (red line, left-hand scale), rates of net photosynthesis (black circles, right-hand scale), and MeSa emission rates (blue squares, right-hand scale, multiplied by 5 for clarity). Rates of net photosynthesis were suppressed for few hours only after the high temperature stress, but MeSa emissions dropped to about 1/5 the day after thermal stress application.

diurnal variations such as observed for constitutive monoterpene emissions cannot be expected.

GLV synthesis and thus GLV emissions require membrane damage (e.g. Croft et al., 1993). Once membrane damage has occurred, GLVs are released independent of the stressor that induced the damage (Heiden et al., 2003). It is therefore reasonable that heat induces GLV emissions if the thermal stress is above a threshold that causes membrane damage. This was shown for common reed (Phragmites australis) by Loreto et al. (2006), for tomato (Solanum lycopersicum) by Copolovici et al. (2012) and also observed in this study for pine and spruce. In four cases of heat application to conifers, the severity of the applied stress was above the threshold for membrane damage (in one case no reliable data on GLV emissions were obtained due to use of GC-FID system). In the other three cases we did not find GLV emissions during the thermal stress episodes, because the applied thermal stress was not high enough.

GLV emissions are related to the degree of membrane damage (Fall et al., 1999; Beauchamp et al., 2005; Behnke et al., 2009). The higher the degree of membrane damage, the higher are the GLV emissions. Assuming that high temperature stress does not initiate a quick repair of damaged membranes consequently leads to the hypothesis that thermal stress cannot cause decreasing GLV emissions. We therefore propose that future heat waves will either increase GLV emissions if temperature is above the threshold or leave them unaffected.

If heat waves impose thermal stress on plants, GLV emissions are the only de novo emissions that may increase with the increasing stress. However, as observed for Scots pine and Norway spruce, GLV emission pulses were at least 2 orders of magnitude lower than the MT emission pulses due to pool damage. GLV emission pulses were observed for several hours only, whereas the increased MT emissions lasted for days to weeks. From this observation we conclude that thermal stress-induced GLV emissions are less important for total BVOC emissions from conifers than the thermal stressinduced changes in MT emissions at least for the investigated tree species, which were all strong MT emitters.

\subsection{Impact of heat on constitutive de novo monoterpene emissions}

Temperature is a key variable in controlling MT emissions from vegetation, and it is widely accepted that MT emissions increase exponentially with temperature. However, if leaf temperature exceeds a certain optimum, de novo MT emissions can drop (e.g. Bertin et al., 1997; Staudt and Bertin, 1998), similar to isoprene emissions (e.g. Guenther et al., 1993). Reductions of isoprene emissions as a consequence of heat are attributed to an overall reduction of biosynthetic activity (Zhang et al., 2009; Zhang and Sharkey, 2009; Niinemets et al., 2010).

Similar to isoprene, de novo MT emissions depend on the activity of the enzymes producing the respective BVOC as well as on substrate delivery. Such enzymes may denature at temperatures above 40 to $45^{\circ} \mathrm{C}$ (Loreto and Schnitzler, 2010; Loreto et al., 2006) or substrate delivery may be reduced. Hence, the observed decreases of de novo MT emissions during heat application can be explained by either mechanism. When constitutive de novo emissions were significantly reduced, they did not recover when returning to normal temperature. The heat-induced effects were not reversible on a time scale of hours to days.

We observed thermal stress-induced decreases of de novo MT emissions from Scots pine, Palestine oak and from European beech, with varying magnitude. In case of Scots pine, the 1,8-cineole emissions diminished and did not recover for days. This implies a long recovery time and thus a long-lasting impact of the thermal stress. For Palestine oak whereof all emissions were of de novo nature, the degree of decrease varied for the different MT species. This was already shown by Staudt and Bertin (1998) who found decreasing emissions of cyclic MT above $40^{\circ} \mathrm{C}$ but still increasing emissions for acyclic MT. For European beech, the thermal stress-induced modifications of MT emissions were moderate despite the high and long-lasting heat application. It is therefore obvious that the impacts of heat on de novo MT emissions from different plant species may differ largely.

Beech, as a species of temperate forests, should be less heat tolerant than Mediterranean species. We nevertheless found comparable decreases of de novo MT emissions after exposing European beech and Palestine oak to $40^{\circ} \mathrm{C}$. Moreover, Bertin et al. (1997) show that MT emissions from the Mediterranean species Holm oak can drop already when the temperature exceeds $35^{\circ} \mathrm{C}$ implying that the plants used in our experiments were less sensitive to thermal stress than Holm oak. But the plants investigated in our experiments 
were well watered, and impacts of heat may strongly depend on the plant water status. Differences in water availability may explain the seemingly higher heat tolerance of European beech compared to Holm oak.

To summarize, temperatures above which de novo MT emissions decrease vary broadly. Such threshold temperatures may depend on the heat sensitivity of the enzymes producing individual MT species, on the heat sensitivity of substrate availability, on the individual plant as well as on the environmental conditions the plant experiences. Therefore general statements on such threshold temperatures are not possible yet. However one general statement can be made: de novo MT emissions decrease when enhanced temperatures act as thermal stress.

\subsection{Impact of heat on monoterpene emissions from pools}

The impacts of thermal stress on pool MT emissions from conifers species differ substantially from those on de novo emissions. Pool MT emissions increased considerably more than expected from the usual exponential temperature dependence. We conclude that the excessively high increase was due to damage of membranes surrounding the resin ducts.

The MT emission pulses were accompanied by a simultaneous pulse of GLV emissions, also indicating membrane damage in the plant. The similar timing between the onset of GLV emissions and increased MT releases suggests that membranes surrounding the resin ducts were also damaged, causing a decrease of the diffusive resistance from the resin ducts to the air. The MTs stored in the large pools of the pine were produced before the ${ }^{13} \mathrm{CO}_{2}$ exposure; therefore, the MT released in excess contained only the natural ${ }^{13} \mathrm{C}$ abundance. No MTs containing excess ${ }^{13} \mathrm{C}$ were synthesized and emitted after exposing the plant to heat. We furthermore did not find such pulses from plants not possessing resin ducts, and we therefore conclude that the pulses in MT release from conifers were due to damage of resin ducts.

Not much data exist regarding the impact of thermal stress on pool MT emissions. Tingey et al. (1980) show a purely exponential increase of MT emissions from slash pine up to a temperature of $46^{\circ} \mathrm{C}$ indicating that this temperature had no irreversible impacts. This seems to be in contrast to our observations for Scots pine where we found MT emission pulses even at lower temperatures. In some cases we also observed no impacts of high temperatures on MT emissions except of the usual exponential increase. Seven of the experiments with thermal stress on conifers were conducted with plants of the same species, and the results listed in Table 3 imply that thresholds above which temperature induces irreversible modifications of BVOC emissions can also differ between individuals. Reasons for the different temperatures above which MT pools are damaged may be differences in water supply, differences in the temperature history of the individual, or differences in the duration of the heat.
As described in the review by Niinemets et al. (2010), the impacts of heat pulses on isoprene emissions depend on the duration of the heat. Short heat pulses may have lower impacts on isoprene emissions than longer-lasting heat periods. Similar behaviour was also observed in this study for pool MT emissions: no irreversible impacts were observed when exposing a plant to $46^{\circ} \mathrm{C}$ for $1 \mathrm{~h}$, whereas irreversible effects were observed when exposing the same individual to $46^{\circ} \mathrm{C}$ for $4 \mathrm{~h}$ (see Table 3, experiments 5 and 6). This observation implies that the duration of a heat exposure is of importance for a threshold when damage of membranes surrounding the resin ducts appears.

Considering that, besides degree and duration of heat, other environmental factors may impact temperature thresholds, it is obvious that exact threshold temperatures or duration after which MT emission pulses appear cannot be provided at this stage. However, it is possible to state that enhanced temperatures either do not affect such pool emissions irreversibly or increase the emissions when the severity of the heat is above the threshold. As global change is assumed to induce longer-lasting heat waves than in the present climate, we suspect that such thermal stress-induced MT releases from MT-storing conifers will be more frequent in the future.

Whether or not future heat waves will cause increases of constitutive MT emissions above or below those predicted by algorithms depends on the fraction of pool emitters and de novo emitters growing in the respective areas. It is expected that MT emissions will increase more than predicted in areas predominantly covered with conifers (pool emitters). They will increase less than predicted in areas with predominantly de novo emitters.

However, such predictions are only valid for time scales of days to weeks. In all cases when the heat acted as thermal stress, it decreased actual MT biosynthesis; i.e. the MT production in conifers was suppressed. This counteracts the increased release of stored MT, and it is not clear at this point which effect prevails on longer time scales. If the collapse of MT biosynthesis and de novo emissions lasts much longer than the emission pulse, the net effect of thermal stress might also be a decrease of emissions.

The experiment with the four Scots pine seedlings showed that conifers can survive such periods of heat and that pool MT emissions will recover within few weeks. It is therefore likely that also the de novo MT emissions will recover after some time. However, so far we have not much data on recovery of de novo emissions.

\subsection{Impact of heat on BVOC emissions induced by biotic stresses}

High emissions of SQT and phenolic BVOC were observed only for Scots pine and Norway spruce showing visible insect infestation, and we conclude that these emissions were induced by the insect attack. The same conclusion was drawn 
by Joó et al. (2011) who measured SQT and MeSa emissions from Douglas fir infested by aphids. We found this effect for Scots pine and Norway spruce, which are widespread species in boreal and temperate European forests. Furthermore, we found the same dominant SQT emissions: $\alpha$ - and $\beta$-farnesene from insect-infested Norway spruce and Scots pine. This indicates that emissions of $\alpha$ - and $\beta$-farnesene as well as MeSa are a quite typical reaction of boreal conifers to aphid infestation.

Impacts of heat or drought on top of biotic stress can only be determined when biotic stress-induced emissions are either constant in time or when the impact of the stress put on top of the biotic stress is so unambiguous that fluctuations of the biotic stress-induced emissions are negligible. We checked for stability of BVOC emissions before applying heat and found that the fluctuations from day to day were by far less than the strong and abrupt changes during and after heat. We therefore conclude that the observed suppression of biotic stress-induced emissions was indeed caused by the heat application.

As indicated by both the low SQT emissions during darkness (Fig. 5) and by the high degree of labelling, SQT emissions were de novo emissions. The low labelling of MeSa indicates that a considerable fraction was produced from a lowlabelled carbon source. We believe that a considerable carbon pool with an exchange time of several hours existed in the plant. Thereof, the aromatic ring of MeSA was synthesized causing the low labelling. But we suggest that at least one of the steps in the cascade of enzymes synthesizing MeSa depends on PPFD causing the pronounced PPFD dependence. Whichever step accounts for this PPFD dependence, we also consider the MeSa emissions as de novo emissions.

A characteristic of biotic stress-induced emissions is their absence in case of stress-free conditions as well as their quick appearance when the plants experience stress. Considering this, it is comprehensible that such emissions cannot originate from diffusion of these compounds out of large storage pools. We therefore believe that all BVOC emissions we observed during biotic stress were de novo emissions. Note that only BVOC emissions originating from plant internal signals are included in this assumption. Possible pulses of MT emissions due to mechanical damage of pools (e.g. by herbivore attack) are excluded here.

The general response of such stress-induced de novo emissions to thermal stress was similar to that of constitutive de novo emissions. In all cases when heat elicited irreversible changes, de novo emissions decreased. An increase was not observed. The reason for the decrease of biotic stressinduced de novo emissions is likely the same as that causing decreases of constitutive de novo MT emissions: a general decrease of the plant performance as a consequence of the heat. The decrease in performance may be due to the denaturation of enzymes, which synthesize the respective VOC, the breakdown of plant internal signalling cascades, or reduction of carbon supply caused by decreased $\mathrm{CO}_{2}$ uptake.
Independent of the exact mechanism, heat exposure decreased the BVOC emissions induced by biotic stress. In cases when biotic stress-induced emissions were stronger than the constitutive MT emissions from conifers, the overall emissions were decreased by the heat (e.g. Fig. 6). The net impact of heat on BVOC emissions from Scots pine and Norway spruce depends on the impacts of biotic stress the plants experience. It is thus not a priori obvious whether thermal stress on conifers increases or decreases total BVOC emissions. The net effect depends on the fraction of pool emissions on the one hand and on the fraction of constitutive and stress-induced de novo emissions on the other hand.

Not much data are reported so far on the impact of heat on biotic stress-induced emissions. Joó et al. (2011) show exponentially increasing emissions of SQT and MeSA with increasing temperature for Douglas fir. This situation is comparable to the cases where we found no GLV emissions and no pool-MT emission pulses. As listed in Table 3 (experiment 7), emissions of MT, SQT and MeSa were not affected irreversibly and GLV emissions were not induced when exposing a Scots pine to $35^{\circ} \mathrm{C}$ for $22 \mathrm{~h}$. Hence there is no difference between the findings of Joó et al. (2011) and the findings reported here; there is just a difference in terming heat stress. We propose to term only those effects as thermal stress-induced that appear on top of the usual exponential temperature dependence and are irreversible on time scales of hours to days.

With respect to impacts of future heat waves on stressinduced de novo BVOC emissions, the situation is somewhat more complex than in case of constitutive de novo emissions. Induction of biotic stress-induced emissions requires activation of the respective biosynthetic pathways. This activation will certainly depend on the plant species, on the kind of infestation and probably also on the degree of infestation. The degree of infestation will also depend on changes of the plant environment with on-going climate change. The development of interactions between plants and their biotic environment is uncertain (Arneth and Niinemets, 2010), and therefore no predictions are possible so far.

\section{Summary and conclusions}

In several cases heat application affected emissions of BVOC irreversibly. To distinguish between reversible temperature impacts and irreversible effects of heat on BVOC emissions, we termed the latter as impacts of thermal stress. Thermal stress strong enough to induce irreversible effects on BVOC emissions affected emissions of different BVOC classes in different ways. Emissions of GLV as well as MT emissions from pools increased due to heat-induced damage of membranes including partial destruction of resin ducts. In contrast, de novo emissions of MT, SQT, and phenolic BVOC decreased. This general trend of decreasing emissions was 
independent of the de novo emissions being constitutive or induced by biotic stress prior to the heat.

We believe that this behaviour was caused by a general decrease of the plant performance, including e.g. denaturation of BVOC synthesizing enzymes or lowered substrate supply. This mechanistic model seems simple as it just requires discrimination between BVOC classes and their basic emission mechanisms to predict trends in emissions following future heat waves. Nevertheless, upscaling is impossible from our studies alone: in all cases the irreversible impacts of heat were only observable above thresholds. Quantitative information on such thresholds as well as on the dependence of these thresholds on other environmental variables is required before future trends in BVOC emissions can be assessed. With such quantitative information models containing parameters for vegetation types, their future spread and future thermal stress episodes might yield trends for the impacts of heat waves on BVOC emissions from vegetation.

But still major information is missing before clear answers with respect to thermal stress-induced modifications of BVOC emissions can be given. In particular the uncertainty regarding development of biotic interactions prevents reliable predictions (Arneth and Niinemets, 2010). The interactions between plants and their biotic environment may vary as the living conditions of aphids or pathogens may be favoured or worsened due to climate change. It is unclear how the whole system will develop under climate change, and therefore our findings provide trends that have to be integrated in a larger context. However, one point is incontrovertible. Future trends of BVOC emissions cannot be estimated using constitutive emissions alone. BVOC emissions induced by biotic stress and their response to climate change have to be considered.

Acknowledgements. The authors would like to acknowledge financial support by the integrated EU projects ECLAIRE (Contract No. 282910) and PEGASOS (Contract No. 265148). Partial funding was provided by the Israel Science Foundation (Grant No. 196/08). Y. R. acknowledges support by the Helen and Martin Kimmel Award for Innovative Investigation.

The service charges for this open access publication have been covered by a Research Centre of the Helmholtz Association.

Edited by: C. Spirig

\section{References}

Arneth, A. and Niinemets Ü.: Induced BVOCs: how to bug our models?, Trends Plant Sci., 15, 118-125, 2010.

Beauchamp, J., Wisthaler, A., Hansel, A., Kleist, E., Miebach, M., Niinemets, Ü., Schurr, U., and Wildt, J.: Ozone induced emissions of biogenic VOC from tobacco: relationships between ozone uptake and emission of LOX products, Plant Cell Environ., 28, 1334-1343, 2005.
Behnke, K., Kleist, E., Uerlings, R., Wildt, J., Rennenberg, H., and Schnitzler, J. P.: RNAi-mediated suppression of isoprene biosynthesis in hybrid poplar impacts ozone tolerance, Tree Physiol., 29, 725-736, 2009.

Bertin, N., Staudt, M., Hansen, U., Seufert, G., Ciccioli, P., Foster, P., Fugit, J.-L., and Torres, L.: Diurnal and seasonal course of monoterpene emissions from Quercus ilex (L.) under natural conditions - applications of light and temperature algorithms, Atmos. Environ., 31, 135-144, 1997.

Carslaw, K. S., Boucher, O., Spracklen, D. V., Mann, G. W., Rae, J. G. L., Woodward, S., and Kulmala, M.: A review of natural aerosol interactions and feedbacks within the Earth system, Atmos. Chem. Phys., 10, 1701-1737, doi:10.5194/acp-10-17012010, 2010.

Chen, I. C., Hill, J. K., Ohlemuller, R., Roy, D. B., and Thomas, C. D.: Rapid range shifts of species associated with high levels of climate warming, Science, 333, 1024-1026, 2011.

Copolovici, L., Kännaste, A., Pazouki, L., and Niinemets, Ü.: Emissions of green leaf volatiles and terpenoids from Solanum lycopersicum are quantitatively related to the severity of cold and heat shock treatments, J. Plant Physiol., 169, 664-672, 2012.

Croft, K. P. C., Jüttner, F., and Slusarenko, A. J.: Volatile products of the lipoxygenase pathway evolved from Phaseolus vulgaris (L.) leaves inoculated with Pseudomonas syringae pv. phaseolicola, Plant Physiol., 101, 13-24, 1993.

Dindorf, T., Kuhn, U., Ganzeveld, L., Schebske, G., Ciccioli, P., Holzke, C., Köble, R., Seufert, G., and Kesselmeier, J.: Significant light and temperature dependent monoterpene emissions from European beech (Fagus sylvatica L.) and their potential impact on the European volatile organic compound budget, J. Geophys. Res. 111, D16305, doi:10.1029/2005JD006751, 2006.

Fall, R., Karl, T., Hansel, A., Jordan, A., and Lindinger, W.: Volatile organic compounds emitted after leaf wounding: On-line analysis by proton-transfer-reaction mass spectrometry, J. Geophys. Res., 104, 15963-15974, 1999.

Ghirardo, A., Koch, K., Taipale, R., Zimmer, I., Schnitzler, J. P., and Rinne, J.: Determination of de novo and pool emissions of terpenes from four common boreal/alpine trees by ${ }^{13} \mathrm{CO}_{2}$ labelling and PTR-MS analysis, Plant Cell Environ., 33, 781-792, 2010.

Guenther, A. B., Zimmerman, P. R., Harley, P. C., Monson, R. K., and Fall, R.: Isoprene and monoterpene emission rate variability: Model evaluation and sensitivity analyses, J. Geophys. Res., 98, 12609-12617, 1993.

Guenther, A., Hewitt, C. N., Erickson, D., Fall, R., Geron, C., Graedel, T., Harley, P., Klinger, L., Lerdau, M., McKay, W. A., Pierce, T., Scholes, B., Steinbrecher, R., Tallamraju, R., Taylor, J., and Zimmerman, P.: A global-model of natural volatile organic-compound emissions, J. Geophys. Res., 100, 88738892, 1995.

Guenther, A. B., Jiang, X., Heald, C. L., Sakulyanontvittaya, T., Duhl, T., Emmons, L. K., and Wang, X.: The Model of Emissions of Gases and Aerosols from Nature version 2.1 (MEGAN2.1): an extended and updated framework for modeling biogenic emissions, Geosci. Model Dev., 5, 1471-1492, doi:10.5194/gmd-51471-2012, 2012.

Hallquist, M., Wenger, J. C., Baltensperger, U., Rudich, Y., Simpson, D., Claeys, M., Dommen, J., Donahue, N. M., George, C., Goldstein, A. H., Hamilton, J. F., Herrmann, H., Hoffmann, T., Iinuma, Y., Jang, M., Jenkin, M. E., Jimenez, J. L., 
Kiendler-Scharr, A., Maenhaut, W., McFiggans, G., Mentel, Th. F., Monod, A., Prévôt, A. S. H., Seinfeld, J. H., Surratt, J. D., Szmigielski, R., and Wildt, J.: The formation, properties and impact of secondary organic aerosol: current and emerging issues, Atmos. Chem. Phys., 9, 5155-5236, doi:10.5194/acp-9-51552009, 2009.

Hamerlynck, E. P. and Knapp, A. K.: Leaf-level responses to light and temperature in two co-occurring Quercus (Fagaceae) species: implications for tree distribution patterns, Forest Ecol. Manag., 68, 149-159, 1994.

Heiden, A. C., Hoffmann, T., Kahl, J., Kley, D., Klockow, D., Langebartels, C., Mehlhorn, H., Sandermann Jr., H., Schraudner, M., Schuh, G., and Wildt, J.: Emission of volatile organic compounds from ozone-exposed plants, Ecol. Appl., 9, 1160-1167, 1999.

Heiden, A. C., Kobel, K., Langebartels, C., Schuh-Thomas, G., and Wildt, J.: Emissions of oxygenated volatile organic compounds from plants, part I: Emissions from lipoxygenase activity, J. Atmos. Chem., 45, 143-172, 2003.

Janson, R. W.: Monoterpene emissions from Scots pine and Norway spruce, J. Geophys. Res., 98, 2839-2850, 1993.

Joó, É., Dewulf, J., Amelynck, C., Schoon, N., Pokorska, O., Simpraga, M., Steppe, K., Aubinet, M., and Van Langenhove, A.: Constitutive versus heat and biotic stress induced BVOC emissions in Pseudotsuga menziesii, Atmos. Environ., 45, 36553662, 2011.

Komenda, M., Kobel, K., Koppmann, R., and Wildt, J.: Comparability of biogenic VOC emission rate measurements under laboratory and ambient conditions at the example of monoterpene emissions from Scots pine (Pinus sylvestris), J. Atmos. Chem., $45,1-23,2003$.

Lathiere, J., Hauglustaine, D. A., De Noblet-Ducoudre, N., Krinner, G., and Folberth, G. A.: Past and future changes in biogenic volatile organic compound emissions simulated with a global dynamic vegetation model, Geophys. Res. Lett., 32, L20818, doi:10.1029/2005GL024164, 2005.

Loreto, F. and Schnitzler, J. P.: Abiotic stresses and induced BVOCs, Trends Plant Sci., 15, 154-166, 2010.

Loreto, F., Ciccioli, P., Cecinato, A., Brancaleoni, E., Frattoni, M., Fabozzi, C., and Tricoli, D.: Evidence of the photosynthetic origin of monoterpene emitted by Quercus ilex L. leaves by ${ }^{13} \mathrm{C}$ labeling, Plant Physiol., 110, 1317-1322, 1996.

Loreto, F., Barta, C., Brilli, F., and Nogues, I.: On the induction of volatile organic compound emissions by plants as a consequence of wounding or fluctuations of light and temperature, Plant Cell Environ., 29, 1820-1828, 2006.

Mentel, Th. F., Wildt, J., Kiendler-Scharr, A., Kleist, E., Tillmann, R., Dal Maso, M., Fisseha, R., Hohaus, Th., Spahn, H., Uerlings, R., Wegener, R., Griffiths, P. T., Dinar, E., Rudich, Y., and Wahner, A.: Photochemical production of aerosols from real plant emissions, Atmos. Chem. Phys., 9, 4387-4406, doi:10.5194/acp9-4387-2009, 2009.

Niinemets, Ü., Arneth, A., Kuhn, U., Monson, R. K., Peñuelas, J., and Staudt, M.: The emission factor of volatile isoprenoids: stress, acclimation, and developmental responses, Biogeosciences, 7, 2203-2223, doi:10.5194/bg-7-2203-2010, 2010.

Peñuelas, J. and Llusiá, J.: Short-term responses of terpene emission rates to experimental changes of PFD in Pinus halepensis and Quercus ilex in summer field conditions, Environ. Exp. Bot., 42,
61-68, 1999.

Schimang, R., Folkers, A., Kleffmann, J., Kleist, E., Miebach, M., and Wildt, J: Uptake of gaseous nitrous acid (HONO) by several plant species, Atmos. Environ., 40, 1324-1335, 2006.

Schnitzler, J. P., Graus, M., Kreuzwieser, J., Heizmann, U., Rennenberg, H., Wisthaler, A., and Hansel, A.: Contribution of different carbon sources to isoprene biosynthesis in poplar leaves, Plant Physiol., 135, 152-160, 2004.

Schuh, G., Heiden, A. C., Hoffmann, T., Kahl, J., Rockel, P., Rudolph, J., and Wildt, J.: Emissions of volatile organic compounds from sunflower and beech: Dependence on temperature and light intensity, J. Atmos. Chem., 27, 291-318, 1997.

Shao, M., von Czapiewski, K., Heiden, A. C., Kobel, K., Komenda, M., Koppman, R., and Wildt, J.: Volatile organic compound emissions from Scots pine: Mechanisms and description by algorithms, J. Geophys. Res., 106, 20483-20491, 2001.

Singsaas, E. L., Laporte, M. M., Shi, J.-Z., Monson, R. K., Bowling, D. R., Johnson, K., Lerdau, M., Jasentuliytana, A., and Sharkey, T. D.: Kinetics of leaf temperature fluctuation affect isoprene emission from red oak (Quercus rubra) leaves, Tree Physiol., 19, 917-924, 1999.

Sitch, S., Cox, P. M., Collins, W. J., and Huntingford, C.: Indirect radiative forcing of climate change through ozone effects on the land-carbon sink, Nature, 448, 791-795, 2007.

Staudt, M. and Bertin, N.: Light and temperature dependence of the emission of cyclic and acyclic monoterpenes from Holm Oak (Quercus ilex L.) leaves, Plant Cell Environ., 21, 385-395, 1998.

Tarvainen, V., Hakola, H., Hellén, H., Bäck, J., Hari, P., and Kulmala, M.: Temperature and light dependence of the VOC emissions of Scots pine, Atmos. Chem. Phys., 5, 989-998, doi:10.5194/acp-5-989-2005, 2005.

Tingey, D. T., Manning, M., Grothaus, L. C., and Burns, W. F.: Influence of light and temperature on monoterpene emission rates from Slash Pine, Plant Physiol., 65, 797-801, 1980.

Trenberth, K. E., Jones, P. D., Ambenje, P., Bojariu, R., Easterling, D., Klein Tank, A., Parker, D., Rahimzadeh, F., Renwick, J. A., Rusticucci, M., Soden, B., and Zhai, P.: Observations: Surface and atmospheric climate change, in: Climate Change 2007: The physical science basis. Contribution of working group I to the fourth assessment report of the Intergovernmental Panel on Climate Change, edited by: Solomon, S., Qin, D., Manning, M., Chen, Z., Marquis, M., Averyt, K. B., Tignor, M., and Miller, H. L., Cambridge University Press, Cambridge, United Kingdom and New York, NY, USA, 2007.

Wolkovich, E. M., Cook, B. I., Allen, J. M., Crimmins, T. M., Betancourt, J. L., Travers, S. E., Pau, S., Regetz, J., Davies, T. J., Kraft, N. J. B., Ault, T. R. Bolmgren, K., Mazer, S. J., McCabe, G. J., McGill, B. J., Parmesan, C., Salamin, N., Schwartz M. D., and Cleland, E. E.: Warming experiments underpredict plant phenological responses to climate change, Nature, 485, 494-497, 2012.

Zhang, R. and Sharkey, T. D.: Photosynthetic electron transport and proton flux under moderate heat stress, Photosynth. Res., 100, 29-43, 2009.

Zhang, R., Cruz, J. A., Kramer, D. M., Magallanes-Lundback, M. E., DellaPenna, D., and Sharkey, T. D.: Moderate heat stress reduces the $\mathrm{pH}$ component of the transthylakoid proton motive force in light-adapted, intact tobacco leaves, Plant Cell Environ., 32, 1538-1547, 2009. 